\title{
Unemployment and social security of the russian agrarian sector: theoretical- methodologic and organizational-practical aspects
}

\author{
Andrei Shilovtsev ${ }^{1,2, *}$, Konstantin Stozhko ${ }^{2}$, Dmitri Stozhko ${ }^{3}$, Oleg Aleksandrov ${ }^{1}$, and \\ Nishakant Ojha ${ }^{4}$ \\ ${ }^{1}$ Ural Federal University named after the first President of Russia B. N. Yeltsin, Yekaterinburg, \\ Russia \\ ${ }^{2}$ Ural State Agrarian University, Yekaterinburg, Russia \\ ${ }^{3}$ Ural State University of Economics, Yekaterinburg, Russia \\ ${ }^{4}$ Institute of Public Administration, Government of India
}

\begin{abstract}
The article provides a detailed analysis of causes and consequences of modern unemployment with reference to the Russian economy as a whole, and, its sector of agricultural production, in particular. The authors explore varied views on the phenomenon of unemployment in economic science. It is largely described as a consequence of a market economy deformation, resulting from the bureaucratization of management, in contrast to certain liberal treatments, focusing on a "free" (market) demand for labour. The authors give grounds for the necessity to abandon the so-called "effective contracts" as inappropriate under the conditions of the current macroeconomic instability and high socio-economic risks; in replacement, they suggest using more intensively the "social" and "fixed-term" labor contracts broadly accepted in the world.
\end{abstract}

\section{Introduction}

Currently, in the situation of the growing macroeconomic instability and uncertainty, as well as the finance, economic, and ecological crises, aggravated by the intensive struggle against the spread of the COVID-19 pandemic and numerous sanctions by Western countries against the Russian Federation (RF), the unemployment rate in Russia is growing steadily. The negative dynamics is driven by a number of factors. Over the last eight years (2012-2020), the jobless rate in Russia has soared and reached its highest level, which requires a detailed analysis of the situation, in view of the existing high risks and macroeconomic turbulence. The research aims to analyze and assess the key factors causing the rise in the RF agricultural (agrarian) unemployment as well as to identify the most productive and effective strategy and methods of reducing it in the national agro-industrial complex (AIC). The paper focuses on analyzing the current unemployment statistics;

\footnotetext{
*Corresponding author: a.shilovtsev@mail.ru
} 
revealing reasons for the unemployment growth; articulating its social consequences impeding a steady socio-economic development of the agro-industrial complex.

\section{Materials and Methods of Research}

The authors used the statistical data provided by the RF Ministry of Agriculture, Ministry of Economic Development and the Federal State Statistics Service. Based on the programoriented and structural-functional methods, there was carried out an expert assessment of the shortcomings impeding effective employment in the AIC in the context of a transition to a new technological structure and innovation development.

\section{Research Outcome}

The recent growth of unemployment in the rural areas of the Russian Federation can be attributed to several factors. First, that is a growing urban concentration in megacities. Experts anticipate, that, globally, the urban population would account for $66 \%$ by 2050 [1]. The tendency will hold, largely, due to a migration of the rural population to megacities. The outflow of the rural population leads to a shortage of well-qualified and skilled staff (mechanics, machine operators, drivers, etc.) as well as the lack of economically active population.

Hence, the process is bound to cause new social challenges and risks. Firstly, there is an aggravating wealth inequality of the rural population, intensified by a limited access to social benefits. The existing non-effective allocation of the land rent has given rise to the situation when the income distribution coefficients (K. Lorenza, K. Ginni, et al) for different rural population groups appeared worse than in previous years.

The situation when a land ownership income, concentrated in hands of a privileged handful of Russian landlords, is adding oil to the fire of social tension in the agricultural sector of the national economy. This significantly reduces the possibilities for agricultural entities to fund innovative activities, depreciation payments, renewal of fixed assets and working assets. Besides, the non-productive luxuries gains are growing, and the earnings are actively transferred abroad [2].

Secondly, there is taking place a financial and industrial capital concentration, intensified by a frontside substitution of labour by the capital of large agricultural holdings, which leads to a further polarization of the rural population [1]. On the one hand, the overall number of farms and cooperatives is decreasing, their performance efficiency is falling. On the other hand, the limited budget of the national agrarian economy is shrinking even more, owing to the intervention from some foreign funds and companies that are buying up the assets of the key stakeholders of the Russian agrarian market.

Due to the above-mentioned, there is every evidence of the social security decline, as far as rural population is concerned. That is manifested by certain examples of the "discriminatory economy". This term was introduced by G. Becker in his publication "The Economics of Discrimination" (1957), where he suggested using the concept of "taste for discrimination" to classify forms of inequality of economic agents (e.g. working conditions, wages, etc.).

As regards the signs of modern economic discrimination against the rural population, the following should be listed: relatively low wages, financing of agro-industrial complex companies on the residual ("left-over") principle, underfinancing of farms, a low rate of added value in the structure of agro food cost, disparity of prices on industrial and agricultural products [3]. 
As a consequence of the facts mentioned, there is observed a shift in the occupational structure of the labour market - from an agricultural to industrial employment. Here is some statistics. In $2014,27.8 \%$ of the RF population were employed in industry and $7.6 \%$ were engaged in the agricultural sector; however, in 2019 the figures were $32.1 \%$ and $6.1 \%$, accordingly. In the Sverdlovsk oblast, for instance, the agro-industrial complex employs fewer than 54,000 inhabitants [3].

Furthermore, the modern unemployment is "getting younger" - an inevitable consequence, when the most economically active population is being "washed out" of the public production. Scarcity of social lift sources offered by the agrarian sector, a significantly lower income of the rural population (against residents in megacities), underdeveloped social infrastructure - these are the factors explaining why young people prefer not to seek employment in agricultural production, do not want to stay in peripheral localities to start a family and to earn a living there.

According to the data delivered by the Federal State Statistics Service, in 2020, the proportion of the unemployed in the Russian Federation amounted to over 5 mln people. The COVID-19 pandemic has caused a dramatic reduction of production, closure of many enterprises, $47.8 \%$ of employees being under the threat of dismissal. Since the outbreak of the pandemic, over a million of people have been laid off. Based on the forecast analysis by the RF Ministry of Economic Development, in the year 2021, there can be expected a slight $5-6 \%$ decrease in the unemployment rate. However, the recent years' experience has shown that the optimistic forecasts made by the Ministry appeared not to work well [4].

Meanwhile, the actual earnings of the Russians have fallen by 3-4\%; the national mass media report on the likelihood of a $10 \%$ or even $20 \%$ drop in the Russian GDP in 20202021. In this view, the Russian business ombudsman V. Titov pronounced straightforwardly that the government measures intended to support the national economy and business had been insufficient [5].

On the whole, there can be identified the following critical consequences of unemployment in the agricultural sector of the Russian economy:

1. Decreased income of the rural population, resulting in growing poverty.

2. Worsening people health caused by both unfavorable natural (ecological) factors and inadequate health care in rural areas.

3. Degeneration of professional qualification, due to the lack of "effective employment" (the term suggested by J.M. Keynes).

4. Incapacity of the national agrarian production to keep up with the requirements of the innovative and creative economy.

Thus, there arises an urgent necessity for developing a focused programme, aimed to provide social protection of the rural population in the given unfavorable conditions. In the modern scientific literature, numerous studies have already been devoted to the development of various aspects of the program concerned $[6 ; 7 ; 8 ; 9]$.

The programme should be built on a solid theoretical and economic foundation. Undeniably, the most justified theory explaining the reasons for unemployment is the concept suggested by the English economist J. Keynes in his world famous book " General Theory of Employment, Interest and Money" (1936). The author was writing it in the midst of the Great Depression, being distressed by its dramatic consequences; that explains why this work can be referred to as a classical self-study guide for state officials, when making attempts to ensure effective employment. According to D. Keynes, the term "effective employment" implies being engaged in production, having a job, one is qualified for, having an optimal labour input/ outcome ratio. The economist claimed that the driving force of effective employment is an effective wage policy, the one that would take into account not only the production outcome, but also the production peculiarities. If to extrapolate this concept to the agrarian economy, it becomes obvious that the wage policy 
in this sector must be shaped so that to take into consideration the severity of working conditions in farming, limited availability of machinery and equipment (with a higher proportion of manual labour), as compared with other sectors of the national economy. This requires a well-conceived and dynamic statecraft to enforce social regulations.

The national wage policy of the social focus must encourage farmers to work with high efficiency. Unfortunately, in the year 2020, an average wage in the agricultural sector of the RF was as low as P32,803, whereas in the industrial sector it made P49,623, and the gap does not seem to be getting smaller. Moreover, given the specific working conditions for people in farming, the gender pay gap is becoming even more dramatic. The national statistics indicates that $71.2 \%$ of the Russians earn a wage below average. In rural areas, the figure is traditionally lower. At present, only $21 \%$ of the working age population of the country consider their work to be fairly-paid.

An effective pay management in the agro food sector must be a priority, since, along with the evident socio-economic consequences of the accelerating unemployment, there can also be observed the significant socio-cultural ones. They arise not only from a regular migration of agrarian population to megacities, they are also caused by the deteriorating crime situation in rural communities, obsolete infrastructure (in contrast to that in cities), etc. It should be noted, that the transformation of the agrarian labour under the modern circumstances is one of the core institutional factors undermining the prestige of agricultural occupation as well as a diploma in agriculture. Even the availability of free housing or a promise of a relocation allowance can hardly encourage higher school graduates to seek employment in rural areas. Labour migrants from neighboring countries cannot change the situation for the better; a rotational shiftwork (for several reasons) being an inadequate replacement of permanent residence either. The Russian village is increasingly becoming abandoned.

\section{Conclusion}

There are different ways to solve the problem of rural areas unemployment. The starting point for the effort: employers ought to accept a transition to the so-called "fixed labour contracts" with employees, those have been in operation in France since 2016. In accordance with the labour agreement concerned, an employer cannot dismiss an employee before a 6- month period. The contract also implies a number of reservations. For instance, an employer is not expected to offer retraining opportunities for the staff. Or, the idea of "social contracts in employment" - "CAE-CUI", i.e. keeping jobs through the payment of social benefits.

Another option to consider is to encourage the advancement of the rural population social security system by concluding the so-called smart contracts (the term suggested by the American scientist N. Szabo). In the situation of the pandemic, and, in view of the remoteness of rural areas, the possibility to conclude smart contracts can significantly save time/ administrative costs and reduce the risk of non-implemented commitments. Certain advantages derive from the basic objectives of the smart contract design. Namely, observability of the contract in process; enforceability - there are well established enforcement mechanisms to invoke fulfillment of contractual commitments; verifiability the ability to prove that the contract has been performed or breached; and uses of new technologies (a blockchain, etc.). As for the smart contract disadvantages, one should mention: an obscure legal status of electronic codes, including uses of the digital media to store information of contracts; the risk of receiving inaccurate information, etc.

Since 2017, smart contracts have been widely used in the EU when calculating social benefits, wages, and in other business-to-business bank transfers. In fact, with the 
development of the digital economy and advancement of IT technologies, the popularity of smart contracts is growing.

Yet in Russia the situation is fundamentally different. In fact, the Russian Federation officials still advocate the concept of "effective contracts" - a product of the national bureaucratic management. Virtually, the contracts like this are intended to quell (to get rid of, to sack) an unwanted employee on the grounds of some far-fetched reasons. Produced by the established staff management policy, it appears a notorious offshoot of management bureaucratization, where top officials are striving to preserve their "rent-seeking" [10]. That is why the word combination "effective contract" or "effective labour contract" sounds ridiculous, i.e. a nonsense figure of speech [11-12].

Thus, in the situation of the rising unemployment, which in its turn triggers a decline in production not only in peripheral localities, but also in large cities, the clear message is: there is an urgent necessity for a full-scale humanization of the labour law in the country. The initial stage on the way should be a de-bureaucratization of the human resources management, with a possibility of excess managers redeployment.

\section{References}

1. V-Shkola, Projections of Scientific and Technological Development of the Russian Federation Agro-Industrial Complex before 2030, 140 (2017)

2. G. Tsagolov, Pol. Ec. Issues, Oligarchy against the Kremlin Nostradamus 4, 159 (2018)

3. K. Stozhko, et al, Ural St UoEc, Foundations of Welfare State 1, 108, 2, 110 (2016)

4. Unemployment in Russia Reached Its Maximum over 8-Year Period (2020) URL/ https://www.rbc.ru/economics/19/06/2020/5eecd9db9a7947e 77b3bc058

5. Titov Allows for GDP Drop by over $10 \%$ in 2020 (2020) URL/ https://www.rbc.ru/economics/08/04/2020/5e8d9c839a794700e3346928

6. L. Efimova, Reg. Ec: 20, 14 (2015)

7. N. Vishnevskaya, Internet J. SoS, 3 (2015)

8. T. Chekanova, MIR, 6, 171 (2015)

9. I. Zaitseva, Politbook, 2, 160 (2017)

10. V. Niskanen, SPb: School of Ec., Milestones of Economic Thought. Welfare Economics and Public Choice. Special Economics of Bureaucracy 4, 477 (2004)

11. S. Eremina, J. of Russian Law 4, 20 (2014)

12. B.A. Voronin, Ya.V. Voronina, N.B. Fateeva, L.N. Petrova, Agrarian Bulletin of the Urals, 9(163), 84-89 (2017) 